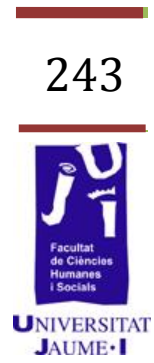

\title{
Imatge i moviment a través de l'art contemporani en Educació Infantil
}

\author{
Marta Almodóvar Fernández \\ al118537@alumail.uji.es \\ Cristina Martínez Raurich \\ al095816@alumail.uji.es \\ Clara Eugenia Rodríguez Marín \\ rodriguc@sg.uji.es \\ Sonia Parra Rodríguez \\ al132870@uji.es \\ Estela Vidal Bellés \\ al095861@uji.es
}


L'experiència que presentem forma part del conjunt d'activitats del projecte d'innovació educativa Espais d'art contemporani como recurs didàctic en Educació Infantil, desenvolupat durant el curs 2011-2012. Els objectius principals del qual van ser, d'una banda, treballar en Educació Artística a través d'experiències amb l'art contemporani en altres contextos i per un altra, generar vies de comunicació i col·laboració entre tres institucions. La investigació es va dur a terme amb un equip integrat per docents de l'Àrea de Didàctica de l'Expressió Plàstica de la Universitat Jaume I (UJI), el responsable del gabinet didàctic de l'Espai d'Art Contemporani de Castelló (EACC), professorat d'Infantil del Col-legi Carmelitas i alumnat de les titulacions de Magisteri. En aquesta comunicació mostrarem el procés de treball amb xiquets/es de segon cicle d'infantil a partir de l'exposició Darcy Lange: estudi d'un artista a la feina, celebrada en l'EACC durant el primer trimestre de 2012. L'exposició era una mostra de la preocupació de l'artista durant la seua trajectòria per documentar el treball diari en diferents països i situacions amb el vídeo i la fotografia. Per tant, dissenyarem activitats per treballar la imatge i el moviment reproduint els mitjans utilitzats per l'artista i el contingut de l'exposició. En una primera activitat, vam treballar els processos bàsics per a l'obtenció d'una fotografia, en una segona, mitjançant jocs, endevinalles i dramatitzacions, els oficis, connectant les peces de l'artista amb la realitat del xiquet/a a través d'objectes familiars. En una tercera, el concepte del moviment amb el conegut experiment $E l$ cavall en moviment del fotògraf i investigador Eadweard J. Muybridge. Finalment, vincularem les experiències de tal manera que tant les aules com l'EACC van constituir llocs d'aprenentatge comunicats.

Paraules clau: Art contemporani, escola, Educació Infantil, universitat, centre d'art, imatge fixa, imatge en moviment.

\section{Introducció}

A mesura que la societat evoluciona, el tema de l'educació entra cada vegada més en escena. L'educació, tal i com l'entén Freire (2009), és a dir, com a praxi, reflexió i acció sobre el món amb l'objectiu d'aconseguir la seua transformació, ha estat present des de temps immemorials. En qualsevol moment, en qualsevol època, tothom educa als seus coetanis per tal que siguen capaços de sobreviure, per tal que es tornen autosuficients i puguen viure de forma independent. Amb el pas del temps, l'educació es va tornar més formal i van començar a sorgir institucions on l'alumnat acudia per tal de ser educat: les escoles. Ara bé, 
siga l'educació formal (dins l'escola) o informal (fóra de l'escola), aquesta ha de considerar que allò que fa que una acció siga educativa no és la producció d'estats finals extrínsecs sinó, més bé, l'activació de qualitats intrínseques que es posen de manifest durant la realització de l'acció. Per tant, no només anem a centrar-nos en els resultats finals de les accions educatives sinó que també anem a valorar el procés seguit per tal d'assolir-los (Elliot, 1988).

El nostre treball, focalitza part de la seua atenció en l'escola però al mateix temps, també dóna importància a aquells espais externs a aquesta que a més poden ajudar a construir l'educació. De fet, la nostra experiència té com a objectiu principal l'establiment de vincles educatius entre institucions que fins al moment han estat independents. D'una banda tenim l'escola, que és el marc habitual on té lloc l'educació formal. D'altra banda, hem considerat la possibilitat de treballar conjuntament amb la universitat i els espais artístics de la nostra ciutat (educació informal). En el primer dels casos, podem dir que I'UJ, mitjançant diversos estudis i investigacions, ja havia estat vinculada a les escoles de la província però no atenent al camp que ens interessa a nosaltres: l'art contemporani. És el cas, per exemple, d'altres projectes presentats en jornades de foment de la investigació d'anys anteriors com "La escuela inclusiva" (Arró, 2011) o "El profesorado ante la escuela inclusiva" (Esteve, 2011). Ara bé, com podríem definir el concepte d'art? Utilitzem les paraules de Marco (2006: 147):

La definición de arte se escapa al ser algo no medible y que se halla profundamente incorporado en el proceso real de percepción, pensamiento, y acción corporal (...) El arte es algo que nos rodea y que nos detenemos a considerar, está presente en todo lo que agrada a nuestro sentido, e invita a la reflexión.

Anteriorment, tampoc s'havia tingut en compte la possibilitat de cohesionar aquesta unió (escola i universitat) amb una tercera, pel que fa als espais artístics. La nostra proposta va ser la d'intentar establir vincles, una comunicació entre espais pel que fa al món de l'educació, concretament de l'educació artística. I a més, el que volíem era tractar d'obrir noves portes a aquest tipus d'educació, donant cabuda a nous plantejaments metodològics. Actualment, l'educació artística forma part del currículum escolar, tal i com la última Llei d'educació (LOE: Llei Orgànica d'Educació) ho va establir a Espanya en el 2006. Ara bé, pel que fa al concepte d'educació artística és necessari aclarir que:

[...] no se basa solamente en el desarrollo de unas habilidades y en la capacidad expresiva, de todos es sabido que en el currículum se contempla como parte importante el conocimiento del arte, y la valoración del patrimonio. [...] Lo que puede considerarse fundamental es la inclusión del Museo en toda esa 
reflexión. El escenario del conocimiento se traslada, sale del aula, considerando al museo o espacio expositivo - la gran escuela - el centro didáctico por excelencia (Marco, 2006: 148).

D'acord amb el que diu aquesta autora, la nostra percepció de l'educació artística ha de tenir en compte tant l'expressió i la producció artística com l'apreciació i valoració d'aquelles obres ja existents. Per a poder fer-ho, serà necessari contextualitzar l'ensenyament; en aquest cas, implica entrar en contacte amb aquells espais que ens puguen facilitar l'observació de produccions artístiques: els centres d'art.

Si atenem al sistema legislatiu, podem dir que l'educació artística queda contemplada. A l'etapa d'Educació Infantil, aquesta queda recollida en la LOE (2006), article 13. Objectius, dins l'apartat f) Desenvolupar habilitats comunicatives en diferents llenguatges i formes d'expressió. Pel que fa a l'Educació Primària, podem observar que a l'article 18 (LOE, 2006) apareix l'assignatura Educació artística. Finalment, a l'Educació Secundària, dins l'article 24 (LOE. 2006) trobem l'assignatura Educació plàstica i visual, que aniria en la mateixa línia. Així doncs, observem la presència de l'educació artística es contínua dins del sistema educatiu actual. Tenint clara la situació de l'art al sistema educatiu del nostre país, podem continuar explicant a quina de les etapes educatives va dirigit aquest projecte: l'etapa infantil (3 a 5 anys). La decisió es fonamenta en la consideració que el mètode de treball seguit en aquest àmbit, pot ser replantejat i enriquit amb noves propostes d'acció.

De la mateixa manera, també és necessari especificar amb quin àmbit de l'art volíem treballar. Com que l'espai artístic que va col-laborar en el projecte va ser l'EACC, el moviment artístic sobre el qual va girar el treball va ser l'art contemporani. Però, què vol dir art contemporani? En paraules de Fontal (2006: 17) aquest seria l'art del postmodernisme, considerant el postmodernisme com el paraigües sota el que queden recollides moltes de les orientacions contemporànies pel que fa a l'art i l'educació artística. Segons (Efland, Freedman i Sthur, 2003: 65-66) es podrien establir una sèrie de cànons estilístics per a l'art contemporani o postmodern:

a) Ús d'una bellesa dissonant o harmonia inharmònica.

b) Rebuig de les idees modernes de sistema compositiu (relació entre les parts i el tot).

c) Pluralisme cultural i polític.

d) Eclecticisme estilístic radical.

e) Acceptació i ús de les noves tecnologies.

f) Interès per qüestions urbanes com el reciclatge.

g) Interès creixent per l'antromorfisme o l'ús de formes humanes en l'art. 
h) Relació entre art del passat i del present: voluntat de fusió i integració.

i) Ús de la doble codificació: ironia, ambigüitat, contradicció.

j) Polivalència i capacitat d'obrir-se a l'entorn, a referències variades i a pluralitat d'associacions.

k) Reinterpretació de la tradició.

l) Creació de noves formes retòriques a partir de modificacions sobre formes artístiques antigues. Si bé aquestos cànons ens serveixen per a fer-nos una idea aproximada de les característiques de l'art contemporani, hem de ser conscients que la diversitat i multiplicitat d'opcions és molt gran. Podem considerar que:

«[...] para aprehender el arte como contemporáneo, tenemos por ende que establecer ciertos criterios, ciertas distinciones que aíslen el conjunto llamado "contemporáneo" de la totalidad de las producciones artísticas. Ahora bien, no podemos buscar estos criterios solamente en el contenido de las obras, su forma, su composición, el empleo de tal o cual material, ni en su pertenencia a tal o cual movimiento de "vanguardia" o no. Por eso, todavía nos vemos enfrentados, en efecto, a la dispersión, a la pluralidad incontrolable de los "ahoras"» (Cauquelin, 2002: 28).

Per al nostre propòsit d'investigació-acció, la flexibilitat que ens proporcionava l'art contemporani, va ser idònia ja que la seua diversitat en la representació ens oferia moltes possibilitats d'acció.

Aquesta investigació sobre educació artística i art contemporani, va girar al voltant de l'exposició de Darcy Lange, artista neozelandès que exposà la seua obra en l'EACC del 20 de gener al 29 d'abril de 2012. Especialitzat en l'escultura, la fotografia, el cine i el vídeo, aquest artista ens va permetre plantejar l'educació artística a l'etapa infantil d'una manera diferent. Tot i que va començar amb l'escultura als anys 60, en 1971 la va abandonar per a dedicar-se al mitjà cinematogràfic. Tant el vídeo com la fotografia li serveixen per a captar i mostrar allò que es torna el seu objecte d'interès: la gent al seu lloc de treball (People at Work). Lange, va començar a fotografiar i gravar a gent mentre aquesta treballava a les fàbriques, tallava llenya al camp o esquilava les ovelles.

De fet, aquest artista va ser un dels precedents pel que fa a la incorporació del pla seqüència per a registrar a temps real, les accions de persones afanyant-se en les seues tasques quotidianes. La experimentació amb les possibilitats estructurals de la imatge en moviment i la imatge fixa, va concloure en un ús paral·lel de la fotografia, el film i el vídeo, emprats simultàniament.

Amb aquesta informació i després d'haver visitat l'exposició a l'EACC, ens vam plantejar com adaptar el context de l'autor a les aules d'infantil. D'entrada, va resultar complex trobar les connexions ja que no teníem 
molt clar com fer que el tema de l'exposició resultarà atractiu per a I'alumnat. En canvi, a mesura que ens vam reunir, vam consensuar què fer; tenint en compte la importància que Lange donava a la imatge i el moviment, el nostre treball es centraria en aquestos aspectes. Al parlar d'imatge, volem referir-nos a la representació visual d'un objecte (en aquest cas persones) mitjançant diferents tècniques: dibuix, pintura, fotografia en el procés a través del qual, almenys un dels elements del sistema que es considera, canvia de posició o d'orientació en l'espai. En aquest cas, ens estaríem referint a la imatge que ens proporciona el vídeo (imatge en moviment) en contraposició a la de la fotografia (imatge fixa). Tot i així, ambdues seran treballades. Per a seguir llegint, només cal tornar a les paraules de la professora Fontal i atendre a la seua forma d'entendre l'art i l'educació, ja que el seu punt de vista ens ha acompanyat durant tot el procés:

[...] arte y educación son dos componentes culturales que surgen de un mismo contexto cultural, que podemos denominar postmodernidad o que, en todo caso, podemos analizar y comprender. Ello nos llevará a asumir referentes comunes entre la creación artística contemporánea, y los planteamientos y reorientaciones desde la educación, y de forma específica, desde la didáctica (Fontal, 2006: 18).

A continuació, exposem més explícitament els objectius d'aquest treball, les activitats que ens van sorgir, la metodologia que vam emprar i sobretot, quins són els resultats i les conclusions que podem extraure sobre aquestos.

\section{Objectius}

L'objectiu fonamental va ser treballar en Educació Artística a través d'experiències amb l'art contemporani en altres contextos per a generar vies de comunicació que consoliden una xarxa de col-laboració entre els tres espais d'aprenentatge: I'Espai d'Art Contemporani de Castelló (EACC), les aules d'educació infantil del Col-legi Carmelitas i les de la Diplomatura de Mestre/a en la universitat. Entre els objectius que ens plantegem establim dos nivells, el primer compartit per totes les parts referit als espais i el segon als recursos humans. Per tant, per un lloc el principal objectiu fou establir una xarxa de comunicació permanent i fluida que permeta consolidar la col-laboració entre les parts per a una continuïtat del projecte. Per altre, transformar els hàbits docents i orientar l'acció educativa cap a la professionalització, d'una manera realista i eficaç. És a dir, plantejar reptes orientats a la millora de la formació professional del alumnat (Jové y Olivera, 2011:180). Els objectius comuns als tres espais són: 
1. Conèixer $\mathrm{i}$ aprendre a través de l'experiència. L'alumnat coneix una realitat per a treballar l'art contemporani en l'escola, al mateix temps que rep un aprenentatge des de l'experimentació.

2. Desenvolupar competències específiques en la didàctica de l'expressió plàstica.

3. Valorar l'art contemporani i les activitats que realitza el gabinet didàctic.

4. Apreciar els processos d'aprenentatge de l'alumnat d'infantil i primària en l'experiència amb l'art contemporani.

Però, plantegem d'altres objectius destinats a cada col·lectiu:

Professorat i professionals:

1. Connectar amb els mestres de l'escola i els futurs mestres en un context artístic.

2. Enriquiment mutu de continguts de les matèries amb la interacció entre el professorat, els tècnics, l'alumnat i els professionals.

3. Detectar les possibilitats reals que permet l'educació artística actual per desenvolupar aquest tipus d'activitats, connectar a les generacions de docents a les aules per a establir debats.

4. Coordinació en la planificació educativa del professorat de l'àrea de Didàctica de l'Expressió Plàstica orientada a l'elaboració de les guies docents.

5. Coordinació entre assignatures de l'àrea facilitant el diàleg de les pràctiques d'aula mitjançant la implementació de tècniques, estratègies i eines d'aprenentatge.

6. Fomentar l'intercanvi d'experiències docents en l'àmbit de la innovació i la docència universitària.

7. Difondre i compartir les experiències i materials d'innovació docent desenvolupats en el projecte de millora mitjançant la participació en les Jornades de Millora, publicacions dels materials o d'altres fòrums que es puguen organitzar per a aquestos menesters a l'entorn de la Universitat Jaume I.

8. Aplicar propostes que permeten interaccionar amb el nostre alumnat, alhora que es treballen algunes de les competències genèriques especificades en l'EEES.

9. Establir contacte amb professionals d'altres universitats i institucions per a futures accions innovadores. 
Alumnat universitari:

1. Fomentar l'aprenentatge autònom des de l'aula virtual, la coordinació i l'experimentació.

2. Responsabilitzar-se del seu aprenentatge, aprendre des de l'experiència, sent receptors, observadors, productors.

3. Incidir en la presa de consciència sobre les funcions professionals com a mestres i mestres.

Alumnat d'infantil:

1. Realitzar activitats que impliquen habilitats manipulatives de caràcter fi: dibuixar, acolorir, retallar, etc.

2. Participar en diferents tallers cooperatius.

3. Desenvolupar l'autoestima, la creativitat i l'empatia a través dels tallers cooperatius.

4. Identificar i valorar obres pictòriques i pintors : Darcy Lange.

5. Gaudir de diferents tècniques plàstiques.

6. Reconéixer diferents professions.

7. Conéixer l'evolució de les càmeres.

8. Acostar a les famílies l'escola a través de l'exposició del mural cooperatiu.

\section{Material i mètode}

La proposta que presentem tracta d'establir una línia de col·laboració entre la universitat, l'escola i l'espai d'art, per tal d'implicar a l'alumnat, al professorat i a professionals dins d'un mateix projecte. Els tres espais involucrats són contextos on es desenvolupa, facilita i complementa el procés d'aprenentatge. En cadascun d'aquestos espais podem adonar-nos com, malgrat les seues diferències estructurals, són llocs compatibles que recolzen l'aprenentatge.

Aquest projecte s'ha desenvolupat durant el curs 2011-2012, on s'inclouen reunions, visites a l'espai d'art, realització de tallers i unes jornades sobre educació artística on intercanviar experiències. No obstant, l'experiència que presentem s'ubica més concretament durant els mesos de Febrer, Març i Abril. Durant la fase dedicada a la preparació de la nostra actuació a l'aula, primerament vam realitzar una visita a I'exposició Darcy Lange: estudi d'un artista a la faena a I'EACC, per tal de plantejar quin tipus d'activitats podíem realitzar a les aules d'infantil. Com que l'exposició, mitjançant fotografies en blanc i negre i documentals, mostrava diferents contextos del món laboral, un tema que ens permetria apropar-nos a tot l'alumnat de forma significativa i motivadora seria els 
oficis. Amb la fi d'adaptar el tema de l'exposició a xiquets i xiquetes de segon cicle d'educació infantil, vam decidir fer primer els tallers a l'escola per clarificaren les idees prèvies de l'alumnat i després, vam continuar amb la visita a l'EACC per tal de relacionar allò que havien fet i aprés a I'aula. A l'escola, el circuit es va realitzar en diferents espais: la seua aula i l'aula de psicomotricitat (on ens vam desplaçar per a fer una de les activitats). En cada aula hi havien 28 xiquets i xiquetes que vam distribuir

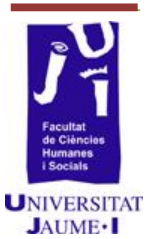
en 4 grups de 7 alumnes cadascun, coordinat per un membre de l'equip d'investigació i alumnat de l'assignatura 044 Taller de Recursos Materials en l'Expressió Plàstica de l'UJI.

Seguidament passem a relatar les pautes de treball emprades per a la implementació en l'escola del taller, amb tres activitats de vint minuts y una hora i mitja de duració.

Taula 1. Ordre de les activitats per grups

\begin{tabular}{|c|c|c|}
\hline Grup A & Grup B & Grup C \\
\hline Aula de psicomotricitat ${ }^{1}$ & Cavall & Jocs \\
\hline Jocs $^{2}$ & Aula de psicomotricitat & Cavall \\
\hline Cavall $^{3}$ & Jocs & Aula de psicomotricitat \\
\hline
\end{tabular}
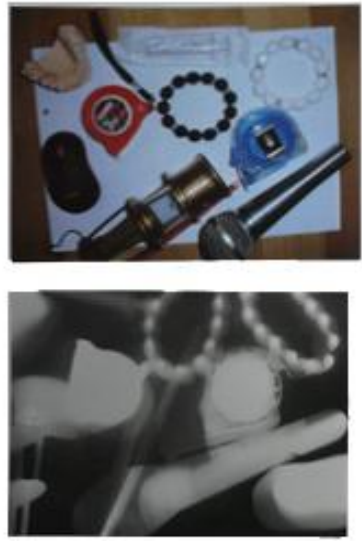
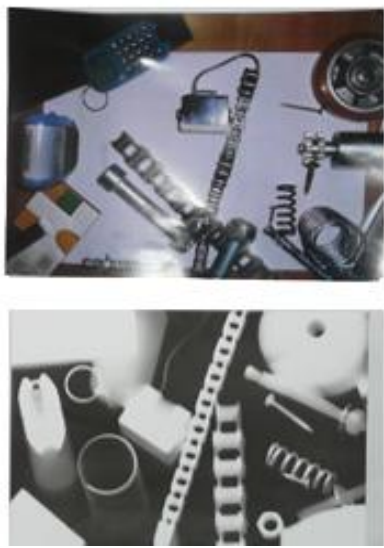

Imatge 1. Raiogrames elaborats en el tallers amb el objectes dels nens i nenes de Educació Infantil

\footnotetext{
${ }^{1}$ Aula de psicomotricitat: aula on ens traslladarem amb els nens/es $\mathrm{i}$ els seus objectes per a elaborar els raiogrames ${ }^{1}$ (Imatge 1 ).

2Jocs: endevinalles i dramatitzacions.

${ }^{3}$ Cavall: representem el moviment a través dels fotogrames de la coneguda animació de El caballo en movimiento de d'Eadweard J. Muybridge (Imatge 2).
} 

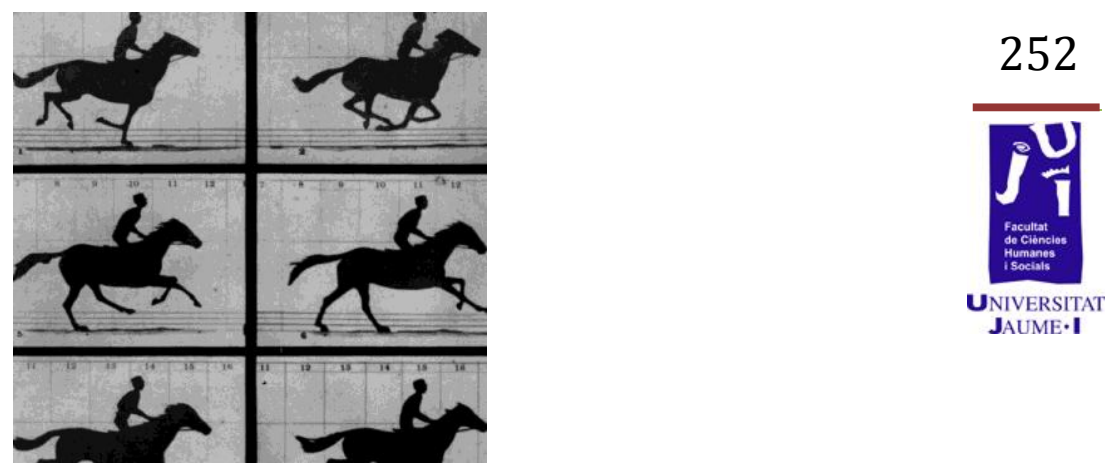

Imatge 2. El caballo en movimiento. Experiment d'Eadweard J. Muybridge, seqüència de mig segon de moviment amb 12 fotografies http://commons.wikimedia.org/wiki/File:Muybridge race horse animated.gif

\section{a) Presentació general en cada aula}

Després d'una breu presentació vam comentar amb els xiquets i xiquetes si sabien el que era una fotografia i vam verbalitzar amb ells/es sobre el fet que fem una foto quan volem recordar a una persona o un moment especial (aniversari, vacances, festes...). Fer una foto és conservar un instant, paralitzar un tros de la realitat. Si férem una fotografia després d'una altra al temps que una persona està en moviment i posteriorment, les veiem ordenades ens n'adonem de les distintes posicions que adopta i si eixes fotos les vérem a molta velocitat estaríem veient el seu moviment.

Antigament no existien les càmeres digitals ni tan sols les més rudimentàries, per tant, les persones no podien retratar les coses que passaven si no era pintant-les. Reforçant el nostre discurs, els vam mostrar reproduccions de quadres d'autors com el francès Millet del segle XIX o Velázquez del segle XVII. Explicant de forma simultània que al llarg del temps van descobrir que per mitjà d'una caixa fosca es podien reflectir les imatges que hi havia fóra d'ella, tenint en compte el temps i la llum. Aquesta caixa es va anomenar càmera estenopeica i va suposar el naixement de la fotografia. A partir d'aquest descobriment, les persones van continuar investigant fins a arribar a l'actualitat on la fotografia, el vídeo, el cine i les noves tecnologies, en general, són part essencial del nostre dia a dia. 


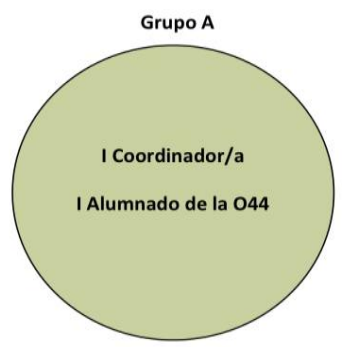

10 Aula psicomotor 20 Juegos 3ㅇ Caballo

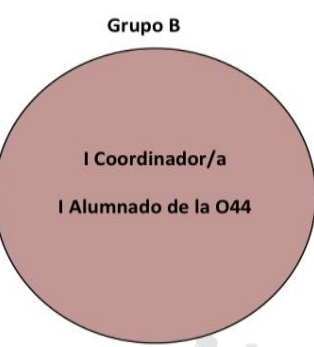

1․ Caballo 20. Aula psicomotor 3ำ Juegos

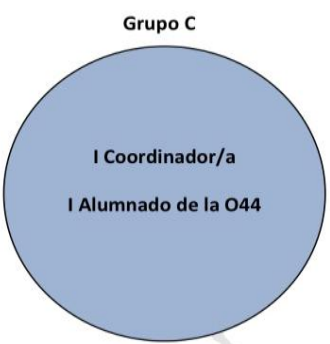

10 Juegos 20 Caballo 3․ Aula psicomotor

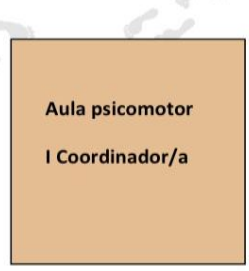

Figura 1. Pautes generals de les activitats

\section{b) Fotogrames del cavall}

Eadweard J. Muybridge (1830-1904, Anglaterra) va ser un dels precursors de la fotografia en moviment. A partir de les seues investigacions, va aconseguir recrear el moviment després de fotografiar al galop una egua anomenada Sally Gardner. A continuació, va pintar els negatius perquè només se serviria de la silueta per a l'estudi i el resultat va ser una seqüència de 12 fotografies que van produir aproximadament mig segon de moviment. Els experiments sobre la cronofotografia Muybridge van servir de base per al posterior invent del cinematògraf i a nosaltres ens ha servit com a referent per a poder explicar la imatge en moviment a l'alumnat.

Detall de les sessions i el material emprat:

\section{$\underline{\text { Activitat del cavall }}$}

Material: fotocòpies del cavall per a cada xiquet/a i gif del moviment del cavall, grapadores i ceres.

Pautes:

1. Reflexió inicial 5 minuts. Observem el vídeo i expliquem que el moviment es genera a partir d'imatges fixes i distribuïm fotocòpies del cavall de El caballo en movimiento.

2. Muntem $(1,2,3,4,5,6,7,8, \ldots$.

3. Grapem.

4. Pintem/decorem el cel. 
Activitat de jocs relacionats amb els oficis

Material: objectes dels oficis. Vam començar en assemblea parlant dels oficis dels seus pares: preguntant quants pares eren mestres, oficinistes, obrers, dentistes, modistes, tenders, periodistes, etc. Després d'aquest xicotet sondeig (els vam deixar que s'expressaren i vam poder

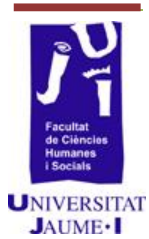
observar el que van estar treballant, abans de la nostra arribada) vam iniciar l'activitat amb un joc de xicotet grup i després en gran grup perquè participarà tota la classe. En funció de les característiques de la classe vam poder alternar l'activitat en diferents opcions:

- Opció 1: amb un grup de 3-5 xiquets podem deixar que toquen un objecte i sense veure-ho que diguen que és, una vegada dita busquem que professió fa referència.

- Opció 2: donar-los, al grup de xiquets/es, un objecte i que representen (per mitjà de dramatització, gestos, accions...) l'ocupació que es relaciona amb l'objecte en qüestió. La resta de la classe ha d'endevinar de quin ofici es tracta. (podem emprar pistes).

- Opció 3: dividim la classe en grups de 7 i a cada grup se li dóna un objecte que represente una professió. Una vegada identificat representen l'objecte, cada xiquet/a ha d'inventar un ús nou d'eixe objecte. Exemple; tenim unes tisores (pare perruquer), ha de buscar altres usos a les tisores (per a tallar paper, per a podar arbres, per a obrir paquets...).

\section{Fotografia en l'aula de psicomotricitat}

En un primer moment aquesta activitat es va plantejar de forma diferent ja que la nostra intenció inicial era fer fotografies dels objectes amb càmeres estenopeiques elaborades per l'equip de la universitat, aleshores ens n'adonem de les dificultats d'aquest experiment, així doncs, vam recórrer a un altra experiència amb la llum que ens oferia més garanties d'èxit, els raiogrames. Tècnica fotogràfica desenvolupada per Man Ray en 1922 consistent en realitzar composicions sense càmera, exposant el paper, prèviament intervingut per objectes diversos, a la llum. Cal dir que aquestes composicions depenen molt de la qualitat dels objectes exposats ja que l'opacitat o transparència d'aquestos són fonamentals en els resultats obtinguts.

Material: bombeta roja, paper fotogràfic i caixes de cartó, cartolina negra gran per a tapar el vidre de la porta d'entrada, zel de precintar, allargador 
per a connectar la bombeta, líquids de revelar (revelador i fixador) i cubetes.

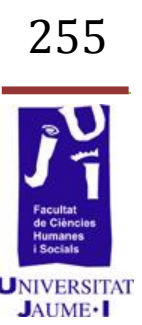

1. Ens vam traslladar amb el grup corresponen a l'aula de psicomotor amb els objectes dels xiquets i xiquetes.

2. Distribuïts en grups de 7 es van situar al voltant d'un cercle que ens va servir de referència per a distribuir als xiquets al voltant d'ell i ficar el paper al centre.

3. L'aula ja estava preparada: persianes baixades, porta tapada. Per tal de deixar l'aula a fosques quan s'apagaren els llums.

4. Abans d'apagar la llum els vam explicar que anàvem a fer i van triar els objectes per a fer la composició fotogràfica.

5. Vam encendre la bombeta roja, vam apagar la llum i vam col·locar el paper sensible al centre del cercle, on cada integrant del grup va ficar l'objecte que havia portat de casa.

6. A continuació vam encendre la llum un segon i la tornarem a apagar.

7. Per últim, a fosques vam recollir els papers en un sobre negre especial per no deixar passar la llum.

8. Les fotografies realitzades les vam portar a la universitat per a revelar-les a un laboratori manual que vam adequar .

\section{Visita didàctica a l'Espai d'Art Contemporani de Castelló (EACC)}

Per continuar les activitats que vam realitzar a l'escola, ens vam traslladar a I'EACC amb l'alumnat del col-legi (Imatge 3) i vam fer una visita guiada amb el responsable del gabinet didàctic del centre d'art. Aquesta activitat els va ajudar a assolir els coneixements tractats al centre ja que, van poder ser observadors i participants actius del recorregut donant sentit a les activitats prèvies. Per començar la visita, i abans d'entrar a l'exposició, el guia els va fer una breu introducció sobre l'autor, el seu origen i la seua trajectòria, animant a l'alumnat a seguir indagant sobre alguns conceptes fins ara desconeguts per a ells/es.

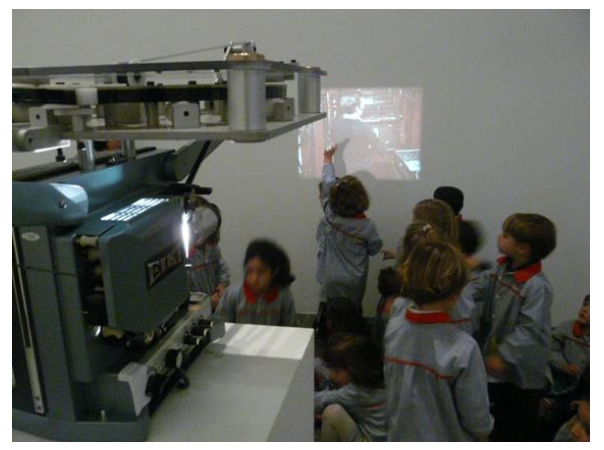

Imatge 3. Visita l'Espai d'Art Contemporani de Castelló amb nens/es de segon cicle d’Educació Infantil 
A continuació, ja dins de l'espai, el guia els va comentar algunes característiques de l'obra exposada, fomentant la observació i la reflexió sobre els vídeos i fotografies que estaven veient i donant peu a la interpretació i verbalització dels continguts d'aquestes. Observant l'obra de Lange l'alumnat va poder distingir les diferències entre la imatge fixa i en moviment i a així, conèixer una mica més les tècniques audiovisuals. De fet, durant el recorregut els xiquets/es van poder interaccionar amb l'espai i d'aquesta manera familiaritzar-se amb un context on elles i ells també tenen cabuda. Per últim, van poder observar i comentar els resultats dels raiogrames que van fer a l'aula de psicomotricitat de l'escola i d'aquesta forma, sentir-se protagonistes també d'aquest espai didàctic.

Els materials utilitzats durant el projecte han sigut nombrosos i diversos, en principi hem comptat amb els recursos de I'UJI i l'obra exposada en I'EACC que ha marcat el punt de referència de les activitats realitzades a l'escola. Per últim, el material que hem necessitat durant el transcurs dels tallers a l'escola com el material fotogràfic, fotocòpies i objectes familiars, com ja hem detallat en les pautes de les activitats.

\section{Resultats}

प-

En aquest apartat exposem les apreciacions de les fases d'observació i experimentació realitzades durant la investigació. Pel que fa a les activitats, ens han semblat superficials a conseqüència de la durada del taller. La falta de disposició de temps es va veure agreujada en l'execució de l'activitat dissenyada per a treballar el concepte del moviment, en la qual vam recórrer al conegut experiment El caballo en movimiento donat que implicava habilitats en la motricitat fina. Arran de la nostra intervenció en cada aula, és podria fer un seguiment de la tasca docent, per a constatar si realment la intervenció ha ajudat al fet que el mestre/a treballe d'una altra forma la part del currículum en la qual hem incidit. Amb referència a l'exposició, cal esmentar la dificultat de la mateixa, en considerar-la poc atractiva i freda tant pels seus elements com per la temàtica. Amb caràcter general, estimem necessari que el treball realitzat no quede en una tasca puntual així com, aprofundir en els continguts que treballen les exposicions.

\section{Discussió i conclusions}

A tall de conclusió abordarem diferents aspectes en referent a la globalitat de tot el projecte. Per una banda, de forma general reflexionarem sobre les dificultats, motivació, recursos humans i la pròpia 
experiència educativa. D'una altra banda, deixarem constància sobre l'extensió del projecte i les futures accions.

D'entrada, durant el procés ens vam trobar amb algunes dificultats donat que, la falta de disposició de temps i les característiques individuals de cada xiquet/a influïen en l'execució de les activitats i per tant, s'haurien d'analitzar i adequar de forma més eficient i flexible per a futures tasques. És important recordar que els recursos humans amb els quals vam comptar en els tres àmbits, han facilitat que les dificultats trobades foren menys significatives, aconseguint així, la integració de l'art contemporani com a part del procés pedagògic. De manera paral·lela, la motivació que proporciona en l'educació la flexibilitat i la innovació ha sigut un dels nostres motors doncs, sens dubte, aquesta metodologia obri més possibilitats a la creativitat.

De manera global, coincidim que a través d'aquesta experiència s'han superat certs prejudicis al voltant de l'educació artística, en l'alumnat de magisteri, considerant que, la gran majoria sol-licita un aprenentatge de la matèria acord a les seves creences. Raó per la qual, al principi del projecte, hi havia resistència cap a didàctiques contemporànies a les quals la gran majoria no havien sigut exposats abans. Per tot açò, considerem que l'educació artística ha de superar el perímetre de l'aula i fomentar un aprenentatge autònom i crític de forma que promoga la responsabilitat i el compromís en aquesta disciplina.

Prenent en consideració aquest últim apartat i recollint les idees llançades per l'equip de treball, en concloure aquest projecte, creiem necessari introduir nous elements en futures accions i repensar l'extensió del projecte. Respecte a l'EACC, podríem treballar en gran grup (més persones) i dissenyar activitats específiques per als visitants de l'espai de forma que s'ampliaria l'oferta de tallers. Certament, es podria ampliar la visió per tal d'introduir la participació de les famílies i el públic. En referent a futures accions, també vam proposar iniciar tallers de formació docent per tal d'enllaçar la visita guiada a I'EACC amb un plantejament posterior de propostes pedagògiques. D'aquesta forma, els i les docents elaborarien activitats d'aula per dur-les a terme ells mateix.

Volem pensar que projectes com aquest, on es generen xarxes de comunicació i coneixement compartit, tenen molt a dir en el futur educatiu d'aquesta disciplina. Cal fer una especial referència al paper del mestre/a dins d'aquest àmbit. Actualment, l'educació artística es troba en inferioritat de condicions dins del currículum escolar, és per això que, la formació primerenca del professorat és clau per la seua defensa en un futur, tant proper com llunyà. En aquest sentit, vam creure necessari plantejar una possible extensió del projecte i, d'aquest debat, vam extraure idees com per exemple, la necessitat d'implicar les noves generacions de mestres en el projecte. Així com també, contactar amb 
escoles properes a l'EACC per tal de difondre el projecte en l'àmbit institucional públic i d'aquesta forma, confrontar els resultats de la present experiència amb d'altres de diferent context i realitat. Encara més, considerem necessari establir el projecte a nivell institucional, és a dir, afermar les relacions establides entre els diversos centres participants d'aquesta experiència. Finalment, i no per això menys important, s'ha de realitzar una tasca de difusió per tal d'augmentar la participació al voltant de l'exposat anteriorment. Per exemple, realitzar seminaris permanents o compartir l'experiència per donar a conèixer la iniciativa en diferents àmbits. Nosaltres hem realitzat la nostra comesa, ara només resta que vosaltres difongueu aquesta experiència.

\section{Bibliografia}

AgRA, M. J. (2007): La educación artística en la escuela. Graó, Barcelona.

ALCAIDE, C. (2003): Expresión Plástica y visual para educadores. ICCE. Colección. Estrategias Educativas, Madrid.

Almau Navarro, A. (2012): Una puerta al arte contemporáneo. Cuadernos de Pedagogía, 424, 16-21.

ARRó, M. i altres (eds.) (2011): El profesorado ante la escuela inclusiva. Publicacions UJi.

Aumont, J. (1992): La imagen. Paidós, Barcelona.

Bosch, E. y otros. (2002): Hacer plástica. Un proceso de diálogos y situaciones. Octaedro- Rosa Sensat, Barcelona.

CAJA, J. (coord.). (2001): La educación visual y plástica hoy. Educar la mirada, la mano y el pensamiento. Graó, Barcelona.

Cauquelin, A. (2002): El arte contemporáneo. Publicacions Cruz O., México.

Dahlbeg, G.; Moss, P.; Pence, A. (2005): Más allá de la calidad en educación infantil. Graó, Barcelona.

DEWEY, J. (2008): El arte como experiencia. Paidós, Barcelona.

EfLAND, A., i altres (eds.) (2003): Educación artística postmoderna" pp 6566 Ed. Paidos, Barcelona. 
EISNER, E. W. (2004): El arte y la creación de la mente: El papel de las artes visuales en la transformación de la conciencia. Paidós, Barcelona.

ELLIOT, J. (1988): Education in the shadow of the Education Reform Act.

ELLIOT, J. (1990): La investigación acción en educación. Morata, Madrid.

ELLIOT, J. (2005): La investigación-acción en educación (5a ed.) Morata,

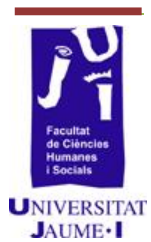
Madrid.

ESTEVE, F.M. i altres (2011): La escuela inclusiva, Publicacions UJI.

FONTAL, O. (2006): Una didáctica creativa y postmoderna para la enseñanza del arte actual. En junta de Castilla y león, Arte contemporáneo y educación: un diálogo abierto (pp. 17) Junta de Castilla y León, España

FReIRE, P. (2009): La educación como práctica de la libertad. Siglo XXI, Madrid (versión original 1969).

GARCíA-Sí́IDO, A. (2003): "Saber ver, una cuestión de aprendizaje: la educación visual a debate». Arte, Individuo, y Sociedad, 15, 61-72.

GARDNER, H. (1994): Educación artística y desarrollo humano. Paidós, Barcelona.

Hernández Belver, M. i SÁnchez Méndez, M. (coord.) (2000): Educación artística y arte infantil. Fundamentos, Madrid.

Jové Moncús, G. i E. Betrián Villas (2012): «Entretejiendo encajes entre la universidad, los centros de arte y las escuelas». Arte, Individuo y Sociedad, 24 (2), 301-314.

Jové Moncús, G. i O. Olivera TABeni (2011): «Viaje a través del tiempo. Diálogos entre obras de arte». Pulso: revista de educación, 34, 159-182.

JovÉ, G i altres (eds.) (2009) EDUC.arte un proyecto de trabajo en red entre universidad, centro de arte y centros educativos». En HUERTA, R. y DE LA CALLE, R. (Eds.), Mentes sensibles. Investigar en educación y en museos (127-138). Universidad de Valencia, Valencia.

Martínez GutiérRez, L. M. i R. GutiéRRez Pérez (1999): Las artes plásticas y su función en la escuela. Algibe, Málaga. 
MARco, P. (2006): El niño ante el arte. En Junta de Castilla y León, Arte contemporáneo y educación: un diálogo abierto (pp. 147) Junta de Castilla y León, España.

Roldán RAmírez, J. i R. MARín Viadel (2012): Metodologías artísticas de investigación en educación. Algibe, Málaga.

TORRES I TARRÉS, M. I R. JUANOLA I ARgEMí (1998): Una manera de enseñar artes plásticas en la escuela. Elsa Peretti Fondation, Barcelona.

VICENTE, M. i altres (eds.)(2012): Darcy Lange: estudio de un artista en su trabajo. Cataclismo. 
